\title{
Utilisation par des vaches laitières de l'herbe de prairie naturelle récoltée en ensilage mi-fané par la technique de l'enrubannage en comparaison de l'ensilage direct et du foin
}

\author{
JP Andrieu, C Demarquilly, J Rouel \\ INRA, SRNH, Unité de la Valeur Alimentaire, Theix, 63122 St-Genès-Champanelle, France
}

Dans les régions où l'herbe constitue l'essentiel des ressources fourragères, le choix du type de récolte en fonction du système de production est souvent une décision importante à prendre. La mise au point de films plastiques étirables de qualité et de machines permettant l'enrubannage automatisé a permis un développement très rapide de cette technique de récolte. Pour connaître la valeur alimentaire du fourrage ainsi récolté pour des vaches laitières, par rapport aux techniques de récolte plus classiquement utilisées que sont l'ensilage en coupe directe et le foin, une étude comparative a été mise en place au Domaine expérimental INRA d'Orcival (altitude : $1100 \mathrm{~m}$ ).

A partir d'une prairie naturelle, fauchée le 23 juin 1992 à l'épiaison du 1er cycle, on a préparé un ensilage direct avec acide formique (EdAF), des balles rondes enrubannées (BRE) et un foin ( $F$ ) (séjour au sol de 2 et 3 jours respectivement pour BRE et F). L'hiver suivant, ces trois fourrages ont été distribués pendant 11 semaines à des lots comparables de 8 vaches laitières (Holstein) en phase décroissante de production, appariées après une période préexpérimentale de 3 semaines. Les performances des vaches (ingestion, production, variation de poids vif) ont été soumises à une analyse de variance avec pour co-variable les paramètres préexpérimentaux. La digestibilité de la matière organique de ces fourrages (dMO) a été mesurée sur moutons. La qualité de conservation a été très bonne pour les deux ensilages. $\mathrm{Le} \mathrm{pH}$, les teneurs en $\mathrm{N}-\mathrm{NH}_{3}$ et $\mathrm{N}$ Soluble (exprimées en $\%$ de $\mathrm{N}$ total) et la teneur en acide acétique ( $g / \mathrm{kg} M S$ ) ont été respectivement pour EdAF et BRE de : 3,8 et 5,$8 ; 6,5$ et 5,$7 ; 49$ et $35 ; 19$ et 2 . La quantité ingérée de fourrage n'a pas été significativement différente entre les traitements, en revanche les vaches recevant EdAF ont produit $2,8 \mathrm{~kg}$ de lait $4 \%$ de plus que celles recevant BRE ou $F(P>0,01)$. Les taux de matière grasse et de matière protéique du lait n'ont pas été différents, par contre les vaches recevant BRE ont perdu du poids contrairement à celle recevant EdAF $(P>0,05)$. En conclusion, dans cet essai où le fourrage a été récolté et conservé dans de très bonnes conditions pour chaque type de récolte, l'ensilage direct avec acide formique a été utilisé plus efficacement par les vaches laitières comparativement aux balles rondes enrubannées et au foin, lesquels ont eu une efficacité comparable. Ces résultats restent à confirmer.
Traitement
Teneur en
dMO (\%)

Performances des vaches laitières :

Quantités ingérées ( $\mathrm{kg} \mathrm{MS} / \mathrm{j})$

$$
\text { - Fourrage }
$$

Production : Lait $4 \%(\mathrm{~kg} / \mathrm{j} / \mathrm{vache})$ Variation de poids vif $(\mathrm{g} / \mathrm{j} / \mathrm{vache})$

\begin{tabular}{cccc} 
EdAF & BRE & $\frac{F}{86,0}-$ \\
22,6 & 65,2 & & 86,5 \\
66,0 & 65,1 & & 65,5 \\
& & \\
13,7 & 13,1 & 13,3 \\
6,6 & 6,5 & 6,6 \\
$25,8^{\mathrm{A}}$ & $23,0^{\mathrm{B}}$ & $23,0^{\mathrm{B}}$ \\
$+206^{\mathrm{a}}$ & $-50^{\mathrm{b}}$ & $+75^{\mathrm{ab}}$ \\
\hline
\end{tabular}

